\title{
İktisadi ve İdari Bilimler Fakültesi Öğrencilerinin Teknolojik Hazırbulunuşlulukları Üzerine Bir Durum Çalışması
}

\author{
A Case Study on Students' Technology Readiness for the \\ Faculty of Economics and Administrative Sciences
}

\author{
Hasan TINMAZ*
}

Öz: Günümüzün hızla gelişen teknolojilerine bir insan olarak yetişebilmek her geçen gün zorlaşmaktadır Yeni teknolojileri kullanabilme yetisine sahip olacak bireylerin bunun öncesinde teknolojik hazırbulunuşluluklarının yüksek olması gerekmektedir. Yapılan çalışmalar teknolojik hazırbulunuşluluğun bir yeni teknolojinin bireydeki algısı, kullanımı ve değerlendirmesi adına öncüllerden birisi olduğunu göstermektedir. Bu çalışma içerisinde alanyazında vurgulandığı şekilde genellikle teknolojik hazırbulunuşluluk çalışmaları adına ihmal edilen İktisadi ve İdari Bilimler Fakültesinin Uluslararası İlişkiler, İktisat ve Lojistik bölüm öğrencilerinin $(n=97)$ birinci sınıfta aldıkları 'Bilgisayar Uygulamaları' dersinin bu öğrencilerin teknolojik hazırbulunuşluk durumlarına etkisini incelemektir. Ders öncesi ve sonrası uygulanan on iki soruluk anket verisi üzerinden normal dağılım görünmemesi nedeniyle parametrik olmayan testler uygulanmıştır. Elde edilen sonuçlara göre teknolojik hazırbulunuşluluk anket maddeleri cinsiyete, bölüme ve ön-son test arasındaki zamana göre istatistiksel olarak anlamlı bir fark göstermektedir. Çalışmaya göre kadın katılımcıların, erkeklere göre kredi kartı numarası vermenin daha tehlikeli olduğunu düşündükleri söylenebilir. Bölümler arasındaki farka bakıldığında farkın Uluslararası İlişkiler ve İktisat bölümleri arasında gözlemlendiğini ve İktisat öğrencilerinin madde madde puanlarının genel olarak Uluslararası İlişkiler öğrencilerinden anlamlı bir şekilde farklılaştığ 1 görülmektedir. Ön-son test anket maddesi karşılaştırmasında ise beş soru üzerinden farklılık gözlendiği ortaya çıkmaktadır. Bu sorularının teknoloji güvenliği üzerine oldukları düşünülürse zaman içerisinde olumlu manada bir teknoloji güvenliğiyle alakalı riskler başta olmak üzere ilgili konularda farkındalık oluşabileceği söylenebilir.

Anahtar Kelimeler: Teknoloji, bilgisayar uygulamaları, hazırbulunuşluluk, kaygı, iktisadi ve idari bilimler, yüksek öğretim

\begin{abstract}
It is getting more difficult for humans to catch up with recent technological advancements. Individuals who will be able to use new technologies must have high technology readiness before anything else. Many studies show that technology readiness is one of the precursors for the perception, use and evaluation of a new technology. The aim of this study is to investigate the change in students' technology readiness of International Relations, Economics and Logistics departments of the Faculty of Economics and Administrative Sciences which is mostly neglected in the literature of technology readiness studies. The sample is delimited to students who were attending 'Computer Applications' course in their freshman year $(n=97)$. Since the normal distribution was not observed over the pre-post tested 12-item survey data, non-parametric tests were applied to dataset. According to analysis results, technological readiness survey showed statistically significant differences according to the gender, department and the time spent between pre and post tests on certain survey items. It can be said that female participants believe more than males that giving credit card numbers to others is dangerous. Besides, it is seen that difference is observed between the departments of International Relations and Economics, where scores of the Economics students differ significantly from the International Relations students in general for certain survey items. When focused on pre-post test survey items, it is unfolded that there were statistically significant differences for five items. Considering that these questions are based on technology security, it can be said that there could be a positive awareness of technology security and possible risks over time.
\end{abstract}

\footnotetext{
* Dr. Öğr. Üyesi, Woosong University, Endicott College of International Studies, Technology Studies, DaejeonSouth Korea, ORCID: 0000-0003-4310-0848, e-posta: htinmaz@endicott.ac.kr
} 
Keywords: Technology, computer applications, readiness, anxiety, economic and administrative sciences, higher education

\section{Giriş}

Modern internet teknolojilerinin ve özellikle sosyal ă̆ servislerinin gelişimi ile bireyler geçmişte hiç karşılaşılmayan oranda birbirleriyle bilgi alışverişinde bulunabilme imkânına sahip olmaktadırlar. $\mathrm{Bu}$ yüzden dijital teknolojilerin kullanımı yaygınlaştıkça kullanıcılar çok daha büyük oranda verilerin aktarımı, depolanması ve işlenmesi gibi sorunlarla karşı karşıya kalmaktadırlar. Bu durum daha çok teknolojiyi bilme ve kullanımına yönelik eğitimler alma ihtiyacını doğurmaktadır. Bu ihtiyacı karşılama adına ilk akla gelen eğitim/öğretim kurumlarıdır. Günümüzde gerek öğrenciler gerekse de bu kurumlar teknolojinin hayatımızın vazgeçilemez bir öğesi olduğunu kesin olarak kabul etmektedir. Bunun bir getirisi olarak da günlük iletişimin teknoloji üzerinden sürdürülmesiyle beraber iletişim kuramamak neredeyse imkansız bir hale gelmiştir (Elitaş ve Koçyiğit, 2015; Öztürk ve Kutlu, 2017; Tunç, Belli ve Aydin, 2017).

Bilgi ve İletişim Teknolojilerinin yaygın kullanımları insanların hayat yaşam kalitelerini attırmanın yanında birtakım güvenlik problemlerinin de yaşanmasına sebebiyet vermektedir. Bilgisayarların daha fazla cihaz, yer ve zamandan bağımsız hale gelmesi ile birlikte güvenlik önemli bir problem haline gelmiştir. Bireyler çok kısıtlı bilişsel kaynakların kullanımını gerektirdiği durumlarda bile kişisel bilgilerini koruma konusunda başarısız olmaktadırlar (Sim, Liginlal ve Khansa, 2012). Sadece bireysel anlamda değil özellikle devletler, endüstri şirketleri ve akademik birimler için bilgi güvenliği dünya çağında ciddi bir sorun olarak algılanmaktadır (He, Yuan ve Yang, 2013; White, Hewitt ve Kruck, 2013). Sözü edilen güvenlik olgusu da farklı teknolojileri doğru ve etkili entegre edebilme becerisinin gerekliliğini ortaya koymaktadır.

Günümüzde birçok basit işlemin bile karmaşık bilgisayar sistemleri ve ağ yapılarını gerektirdiği düşünüldüğünde üniversitelerde bilgisayar kullanımı ilgili derslerin yer alması kaçınılmazdır. Günümüz gelişen teknolojilerini düşündüğümüzde teknoloji ile ilgili çıkarımlar birden fazla akademik disiplini kapsamalıdır (Nielsen ve Welch, 2003). Bir başka deyişle, herhangi bir mesleğin ya da üniversite akademik çalışma alanının teknolojilerden uzak kalması imkânsızdır. Hatta Lomo-David ve diğerleri (2011) araştırmaları sonucunda öğrencilerin hangi bölümde öğrenim gördüklerine bakılmaksızın teknoloji ile ilgili kullanım ve güvenlik gibi bilgilerin diğer konular gibi öğretim programlarında yer almasının gerektiğini ve böylece hem üniversite içerisinde hem de gelecek yaşantılarında teknoloji kullanımlarının daha dikkatli olacağını öngörmüşlerdir. Aynı şekilde White, Hewitt ve Kruck (2013) çalışmalarında mevcut üniversite öğrencilerinin geleceğin kullanıcıları aynı zamanda da veri ve sistemlerin koruyucuları olduğunu belirterek teknoloji ile alakalı olarak bilgi sistemleri ve güvenlik konularının öğretiminin üniversiteler için önemini vurgulamışlardır.

Hızla değişen dünyada insanoğlu ortaya çıkan teknolojik gelişmelere adapte olabilmek adına çok fazla çaba sarfetmektedir. Ortaya çıkan sayısız bilgi ve iletişim teknolojileri araçları toplumun her kesimine hitap eder bir hal almakta ve yoğun teknolojik bilgi edinim süreçlerini tetiklemektedir. Bunun bir sonucu olarak da farklı sosyal gruplarda ve farklı meslek dallarında derinden değişimler gözlenmektedir (Özgan ve Tekin, 2011). Bu nedenle teknolojik hazırbulunuşluluk tüm zamanlardan daha önemli bir kavram, olgu ve kazanım olarak ortaya çıkmaktadır.

Genel olarak tanıma bakıldığında, Sönmez ve Akgül (2015) hazırbulunuşluluğu “... herhangi bir etkinliği yapmaya bilişsel, duyuşsal, sosyal ve psikomotor olarak hazır olmadır" (s. 307) şeklinde tanımlamaktadır. Diğer bir ifadeyle, herhangi bir işin gerçekleşebilmesi için, işi yapacak olan bireyin gerekli olan yetkinliğe sahip olup olmama durumudur. Özelde tanıma bakıldığında ise Ling ve Moi (2007) teknolojik hazırbulunuşluluğunu bireylerin özel ve iş yaşantılarında hedeflere ulaşmak için yeni teknolojileri benimsemesi ve kullanma eğilimi olarak tanımlamaktadır. Bir başka deyişle, teknoloji hazırbulunuşluluğu, yeni bir teknoloji seviyesine girmeye hazır olmaktır (Nugroho, Susilo, Fajar ve Rahmawati, 2017). 
Teknolojik hazırbulunuşlulukları daha yüksek olan öğrencilerin daha fazla güven ve motivasyona sahip oldukları ve teknolojiyi öğrenme süreçlerinin sorumluluğunu ve kontrolünü taşımaya yönelik daha fazla isteğe sahip oldukları söylenebilir (Lee, Yeung ve Ip, 2017). Günümüzde öğrencilerin, bir teknoloji öğrenme adına istekli olmaları ya da olmamaları, bir teknolojiyi öğrenmeye istekli olup olmamaları durumları veyahut bir teknolojiyi kabul edip etmemeleri, onların teknolojik hazırbulunuşlulukları ile doğrudan ilişsilidir (Sönmez ve Akgül, 2015). Parasuraman (2000) teknolojik hazırbulunuşluluğu teşvik eden ve engelleyen etmenler olarak iki ana grupta tanımlamaktadır. Teşvik edici faktör içerisinde iyimserlik durumu ve yenilikçi olma özellikleri tanımlanmaktadır. Engelleyici grupta ise rahatsız olma durumu ve güvensizlik hissi yer almaktadır.

Alanyazında sıklıkla vurgulanan teknolojinin hızlı gelişim eğrisi doğal olarak günümüz bireylerinin de değişimlerine ve beklentilerinin farklılaşmasına sebep olacaktır. Bu değişim bireylerin eğitim süreçlerine de yansıyacak ve bir sonucu olarak eğitim kurumları da teknoloji ile olan ilişkilerini kuvvetlendirecek ve öğrencilerinin teknolojik gelişimlerini de sağlamakla mükellef olacaklardır (Elitaş ve Koçyiğit, 2015). Bu sorumluluklar içerisinde kendi öğrencilerinin hızla evrilmekte olan teknolojileri kullanma ve farklı disiplinlere entegre etmek noktalarında hazır olup olmadıklarını tespit etmek ve sonuçlara paralel düzenlemeler yapmak da yer alacaktır. Bu nedenle günümüz üniversitelerinin teknolojik hazırbulunuşluluk konusunda öğrencilerini hazırlamak adına ellerinden gelenin en iyisini yapmaları gerektiği açıkça ortadadır.

Özgan ve Tekin (2011) teknolojik hazırbulunuşluluk konusunda önemli bir noktayı vurgulamaktadır; öğrenci kendi hazırbulunuşluluğunun ötesinde olan bir bilgiyi öğrenemez. Bu sebeple bir derse ait öğrencinin hazırbulunuşluluğunun belirlenmesi demek o dersin işleyişinin ve öğrenci doğrudan başarısının olumlu etkilenmesi demektir. Eğer hazırbulunuşluluğuna göre bir ayarlama yapılmazsa, diğer bir ifadeyle hazırbulunuşluluğunu aşan ya da yakalayamayan derslerde öğrencinin motivasyonu düşük olacağından dersi dinlememe gibi yönetimsel sorunlar ortaya çıkacak ve sınıf içi ortam olumsuz etkilenecektir.

Bir fakülte bünyesindeki öğrencilerin memnuniyetlerini belirleme adına yapılan çalışmada, Şahin (2009) altı önemli faktör tanımlamış ve bu faktörlerden birisinin teknolojik alt yapı olarak belirtmiştir. Diğer bir ifadeyle, öğrencilerin fakülte bünyesinde gördüğü teknolojik olanaklar ve teknolojinin kullanımı onların memnuniyetlerini belirleme de önemli bir faktör olarak tanımlanmıştır. Son yıllarda sayısı hızlıca artan devlet ve vakıf üniversitelerine bağlı İktisadi ve İdari Bilimler fakülteleri (bkz. Tablo 1) ve onlara bağlı olan bölümlerin bir sonucu olarak ortaya çıkan rekabetçi ortam içerisinde (Erdoğan ve Bulut, 2015) öğrencilerin durumlarının incelenmesi ve iyileştirmeye yönelik çalışmalar yapılması kaçınılmazdır. Günümüzde teknolojiyi bilmenin ve kullanmanın da ne kadar önemli bir fark yarattığını da göz önünde bulundurursak, öğrencilerin teknolojik hazırbulunuşluluklarının değerlendirilmesi ve arttırılması yönelik çözümlerin önerilmesi son derece önem kazanmaktadır.

Varıcı ve Bulut (2015) İktisadi ve İdari Bilimler Fakültesi bünyesinde teknoloji kullanımının başta muhasebe dersi gibi finansal okuryazarlık gerektiren temel dersler olmak üzere diğer derslere de olumlu katkı yapacağını belirtmiştir. Özellikle de bu fakülte öğrencilerinin derslere karşı olan endişelerinin azalması noktasında teknolojinin en büyül olanaklarından olan bilgisayarların kullanılması özellikle önerilmektedir. Bu nedenle İktisadi ve İdari Bilimler Fakültesi öğrencilerinin teknolojiye yaklaşımlarını belirleyen öncüllerden birisi olarak teknolojik hazırbulunuşluluk oldukça önem taşımaktadır.

Lee, Yeung ve Ip (2017) çalışmalarının sonunda önemli bir noktaya vurgu yapmaktadır; öğrencilerin hazırbulunuşluluklarını benzer kabul etmek hatalı bir yaklaşım olacaktır. Kendi çalışmaları da hazırbulunuşluluk üzerinden öğrencilerde çoklu düzeyde farklılaşmanın olduğunu göstermektedir. Örneğin, öğrencilerin daha önceki okullarındaki pedagojik yaklaşımın ve yetiştirilme şekillerinin hazırbulunuşluluk üzerinde ciddi etkisi olduğu gözlenmiştir (Özgan ve Tekin (2011) de aynı sonucu vurgulamaktadır). Lee, Yeung ve Ip (2017) çalışmalarında öğrencinin öğrenme stilinin hazırbulunuşluluk adına bir fark yarattı̆̆ı görülse de, yaş ve cinsiyetin anlamlı bir ilişki göstermediği tespit edilmiştir. 
Teknolojik hazırbuluşluluğunun farklı değişkenlerle etkileşimi konusunda alanyazında farklılıklar tespit edilmektedir. Örneğin; Tsourela ve Roumeliotis (2015) çalışmalarının sonunda teknolojik hazırbulunuşluluk, cinsiyet ve yaş değişkenlerinin gerçek hayattaki teknoloji kullanımı ve kullanma isteğini etkilediğini tespit etmişlerdir. Badri ve diğerleri (2014) teknoloji hazırbuluşluluğunu etkileyen faktörler üzerindeki çalışmalarında, bu olgunun cinsiyet, kültür, yaş ve daha önceki eğitim yaşantıları değişkenlerine göre farklılıklar gösterdiğini söylemektedir. Örneğin, yaptıkları çalışmanın sonucunda erkeklerin kadınlara göre daha ileri teknolojik hazırbulunuşluluğa sahip olduklarını söylemektedirler. Aynı şekilde, Moftakhari (2013) yüksek lisans tezi çalışmasının sonuçları arasında erkeklerin teknolojik hazırbulunuşluluklarının kadınlardan yüksek olduğundan söz etmektedir. Bunun yanında, yine aynı çalışma içerisinde teknolojik hazırbulunuşluluğunun üniversitede okunan bölümlere göre ciddi farklılaştı̆ğını söylemektedir. Diğer bir çalışmada ise, Hung, Chou, Chen ve Own (2010) ise üniversitedeki eğitim yılının teknolojik hazırbulunuşluluk üzerinde bir etkisi olduğunu belirtmektedir. Üçüncü ve dördüncü sınıf öğrencilerinin birinci ve ikinci sınıf öğrencilerine göre çok daha yüksek teknolojik hazırbulunuşluluk sergilediği tespit edilmiştir.

Alanyazında bilgisayar kullanımı ve bilgisayar teknolojilerine yönelik eğilim ve davranışların cinsiyet değişkeni üzerinden ölçüldüğü çalışmalarda hem erkeklerin hem de kadınların eğilimleri hakkında farklı sonuçlar elde edildiğini göstermektedir. He ve Freeman (2010) işletme bölümünde öğrenim gören üniversite öğrencileri üzerinde yaptıkları çalışma sonucunda kadınların erkeklere oranla daha az öğrenmeleri ve alıştırma yapmaları sonucu bilgisayara karşı daha az kendilerinden emin olduklarını ve bilgisayar kullanırken kaygı düzeylerinin daha fazla olduğu sonucuna varmışlardır. Benzer şekilde Walstrom, Thomas ve Weber (2010) işletme öğrencileri üzerinde gerçekleştirdikleri çalışma ile kadınların bilgisayar ve bilgi teknolojileri ile daha az deneyim sahibi olmalarından dolayı karamsarlık yaşadıklarını bulmuşlar ve sorunun çözümü için de eğitimsel farkındalığın arttırılmasını önermişlerdir.

Ayrıca, Lin, Shih ve Sher (2007) çevrimiçi hizmet alınan web sitelerinin müşteri üzerinde yaptıkları çalışmalarında algılanan kullanışlılık ve kullanım kolaylığı konusunda teknolojik hazırbulunuşluluğunun aracı rolü oynadığını tespit etmişlerdir. Ayrıca, teknolojik hazırbulunuşluluk, tüketicilerin teknoloji kullanımına yönelik algılarını ve beklentilerini etkilerken ve yüksek teknolojik hazırbulunuşluluğa sahip müşteriler, ellerindeki teknolojik araç gereçlerin yüksek faydası olduğu algısına sahip olmaktadır (Chung, Han ve Joun, 2015). Buradan çıkarılacak sonuç teknolojik hazırbulunuşluluğun sadece öğretim hayatı adına değil genel olarak hayattaki teknoloji kullanımı konusunda önem taşıdığıdır.

Günümüzün ve geleceğin web tabanlı çalışma ortamlarında başarılı olabilmek adına öğrencilerin teknik beceri, motivasyon ve teknolojiye erişim konusunda sürecin verimliliği ve etkililiği bağlamında teknolojik hazırbulunuşluluklarının yüksek olması önemlidir (Yağc1, Sirakaya ve Özüdoğru, 2015). Örneğin; Amron, Ibrahim ve Chuprat (2017) bulut bilişim kullanımı veya bulut bilişimine en çok katkıda bulunan faktörler konusunda ilk sırada bireylerin teknolojik hazırbuluşluklarından söz etmektedir. Böylesi ileri teknolojilerin etkin kullanımı adına bireylerde bir teknolojik hazıroluş durumu var olup olmaması çok şeyi değiştirecektir.

Sonuç olarak, günümüzde okulların okuma yazma veya matematik gibi temel ihtiyaçların yanına teknolojik hazırbuluşluluğu da ekleyerek eğitim olanakları sunması gerekmektedir (Ratliff, 2009). Okulun öğrenciye vereceği güçlü destek, teknolojik hazırbulunuşluluğunu olumsuz etkileyebilecek olan güvensizlik ve rahatsızlık faktörlerini ortadan kaldırabilir (Nugroho ve Fajar, 2017). Ayrıca, teknolojik hazırbulunuşluğu konusunda devlet ve devlet stratejileri de önemli bir rol oynamaktadır (Nugroho, Susilo, Fajar ve Rahmawati, 2017).

\section{Amaç}

Alanyazın incelendiğinde yapılan teknoloji hazırbulunuşluluğu çalışmalarında İktisadi İdari Bilimler Fakültelerinin ihmal edildiği görülmektedir (Erdoğan ve Bulut, 2015). Ayrıca yine alanyazına bakıldığında öğrencilerin teknolojik hazırbulunuşluluklarının ve farklı kişisel özellikleriyle olan ilişkisinin yeterli miktarda araştırılmadığı ortaya çıkmaktadır (Lee, Yeung ve 
Ip, 2017). Westjohn, Arnold, Magnusson, Zdravkovic ve Zhou (2009) kültürün teknolojik hazırbulunuşluluk üzerinde önemli bir etkisi olduğunu belirtmektedir. Bu nedenle Türkiye odaklı bu çalışmanın başka ülkelerdeki verilere bakarak kültür değişkeni adına da bir katkıda bulunması beklenmektedir.

Tüm bunların sonucu olarak, halihazırdaki bu araştırmanın amacı, bir vakıf üniversitesi bünyesindeki İktisadi İdari Bilimler Fakültesinin üç ana bölümünün (Uluslararası İlişkiler, İktisat ve Lojistik) öğrencilerinin aldığı 'Bilgisayar Uygulamaları' dersinin öğrencilerin teknoloji hazırbulunuşluluğuna katkısı olup olmadığını araştırmaktır. Bu genel amaç bünyesinde araştırmada aşăğdaki sorulara yanıt aranmaktadır:

1. Öğrencilerin ders öncesi ve sonrası teknolojik hazırbulunuşlulukları nasıldır?

2. Öğrencilerin teknolojik hazırbulunuşlulukları cinsiyet ve bölüm değişkenlerine göre anlamlı bir fark göstermekte midir?

\section{Yöntem}

\section{Araştırma modeli}

Bu çalışmanın genel amacı İktisadi İdari Bilimler Fakültesi bünyesinde yer alan öğrencilerin teknolojik hazırbulunuşluluklarının aldıkları Bilgisayar Uygulamaları dersi ile değiş̧im gösterip göstermediğini ortaya çıkarmaktır. Bu amaca hizmet etmek üzere yarı-deneysel nicel araştırma yöntemleri içerisinden ön test - son test ilişkili örneklem araştırma deseni tercih edilmiştir. Araştırmacı, gerek fakülte yönetiminden gerekse de dersi veren öğretim üyesinden ders öncesi ve sonrası anket uygulayabilmek için sözlü ve yazılı izin almıştır. Alınan izne paralel olarak, dersin ilk haftasındaki ikinci ders saatinde (ilk saatinde öğretim üyesinin dersi tanıtmasının ardından) ve son haftasındaki final sınavı öncesindeki son saatinde öğrencilere çalışma anketi verilmiş ve veri toplanmıştır. Daha sonra toplanan veri SPSS yazılımına girilmiş, gerekli analizler ve yorumlamalar yapılmıştır.

\section{Örneklem}

Türkiye içerisinde İktisadi İdari Bilimler çerçevesinde içerisinde yer alan farklı bölümlerde okumakta olan 443211 öğrenci bulunmaktadır (Yükseköğretim Bilgi Yönetim Sistemi, 2018). Tablo 1'den de görülebileceği gibi bu çalışmayla alakalı olarak üç farklı fakülte tespit edilmiştir; İktisadi İdari ve Sosyal Bilimler Fakültesi, İktisadi ve İdari Bilimler Fakültesi ve İktisat Fakültesi. Tablodan da görülebileceği gibi kayıtlı olan 373434 öğrencinin yanı sıra 20172018 sezonundan 69777 ögrenci daha bu fakültelere kayıt yaptırmıştır.

Tablo 1.

2017-2018 YüksekÖğretim Öğrenci Sayıları ve İlgili Fakültelere Dağılımları

\begin{tabular}{lcccccccc}
\hline \multirow{2}{*}{ Fakülte } & \multicolumn{2}{c}{ Birim } & \multicolumn{3}{c}{ Yeni Kayıt } & \multicolumn{4}{c}{ Halihazırda Kayıtlı } \\
& Sayıs1 & Erkek & Kadın & Toplam & Erkek & Kadın & Toplam \\
\hline $\begin{array}{l}\text { İktisadi İdari ve Sosyal Bilimler } \\
\text { Fakültesi }\end{array}$ & 13 & 1857 & 1975 & 3832 & 7817 & 8392 & 16209 \\
\hline İktisadi ve İdari Bilimler Fakültesi & 119 & 33703 & 29985 & 63688 & 176375 & 163836 & 340211 \\
\hline İktisat Fakültesi & 3 & 1111 & 1146 & 2257 & 9084 & 7930 & 17014 \\
\hline Toplam & 135 & 36671 & 33106 & 69777 & 193276 & 180158 & 373434 \\
\hline
\end{tabular}

Bu çalışmada Fraenkel ve Wallen (2000) tarafindan önerilen erişilebilir örneklem tekniği uygulanmıştır. Bunun bir sonucu olarak araştırmacı İstanbul ilindeki bir vakıf üniversitesindeki İktisadi İdari Bilimler Fakültesinin üç farklı bölümünün (Uluslararası İlişkiler, İktisat ve Lojistik) birinci sınıf ikinci dönemde almakta oldukları Bilgisayar Uygulamaları dersinin öğrencilerine $(n=97)$ erişmiştir.

Bilgisayar Uygulamaları dersi öğrencilerin okul ve iş hayatında bilgisayarlardan, kelime işlemci yazılımlarından, hesaplama tablolarından, sunum programlarından ve Internet'ten nasıl 
faydalanabilecekleri konusunda bilgi sahibi olmalarını hedefleyen bir ders olarak tanımlanmaktadır. Bu ders aynı öğretim planı takip edilerek üç farklı bölüm için aynı ögretim üyesi tarafindan haftada üç saat olarak farklı gruplarda gerçekleşmektedir.

\section{Veri toplama aracı}

Araştırmacının kendisine ait olmayan bir ders içerisindeki veri toplarken yaşayabileceği en önemli sorunlardan bir tanesi de zamandır. Diğer bir ifadeyle, bir başka öğretim üyesinin dersinden veri toplamak için çok kısa zamanı bulunmaktadır. Bu nedenle araştırmacı teknolojik hazırbulunuşluluk çalışmaları içerisinden en az soruyla en etkin ölçümü yapabileceği Liljander, Gillberg, Gummerus ve Riel (2006) tarafindan Parasuraman (2000) taban alınarak geliştirilmiş anketi kullanmıştır. Anket on iki sorudan oluşmakta ve 5li Likert tabanında 'kesinlikle katılıyorum' ve 'kesinlikle katılmıyorum' arasındaki seçeneklerden oluşmaktadır. Araştırmacı bu çalışma içerisinde örneklem sayısının yetersizliği nedeniyle Türkçe geçerlilik (özel olarak faktör analizi) çalışması yapamadığından dolayı anket maddelerini tek tek bağımsız olarak incelemiştir.

Son olarak, anketin öncesinde öğrencilere dört temel demografik soru sunulmaktadır; cinsiyet, bölüm, bilgisayar sahip olup olmama ve bilgisayarın türü (masaüstü veya dizüstü). Kullanılan anketin Türkçe uyarlaması araştırmacı tarafından yapılmış ve biri Türk dili uzmanı birisi de alan uzmanı olmak üzere iki farklı ögretim elemanına kontrol ettirilmiştir.

\section{Verilerin çözümlenmesi}

Kâğıt üzerinde toplanan veriler ilk olarak SPSS yazılımına girilmiş ve aykırı değerler, eksik veriler veya veri girişi hatalarıyla ilgili sorunları tespit etmek adına detaylı olarak kontrol edilmiştir. Devamında ilk dört demografik soru adına frekans ve yüzde dağılımları hesaplanmıştır.

Daha sonra anket üzerinde ilk olarak ön test ve son test adına ayrı ayrı olmak üzere verilerin dağılımlarını görmek adına Normallik Testi uygulanmıştır. Çıkan tablo içerisindeki hem Kolmogorov-Smirnov hem de Shapiro-Wilk testleri sonuçları istatistiksel anlamlılık değeri olan 0.05 'ın çok altında çıkmaktadır. Bu durumda normal dağılım olduğu null hipotezi red edilerek tanımlı bölümler için \%95 güven aralığında veriler normal dağılım göstermemektedir. $\mathrm{Bu}$ sebeple, çalışma içerisinde parametrik olmayan (non-parametrik) testlerin kullanılmasına karar verilmiştir. Bu doğrultuda cinsiyetler arası fark için "ilişkisiz ölçümler için Mann Whitney U test", bölümler arasındaki farklar için "ilişkisiz ölçümler için Kruskal Wallis H-test" ve son olarak ön-son test arası farklar için "ilişskili ölçümler için Wilcoxon işaretli sıralar testi" uygulanmıştır.

\section{Bulgular}

Tüm katılımcılarının ( $\mathrm{n}=97$ ) bilgisayar sahibi ( $\mathrm{n}=53$ masaüstü, $\mathrm{n}=68$ dizüstü ve $\mathrm{n}=26$ hem masaüstü hem de dizüstï) olduğu "Teknoloji Hazırbuluşluluğu Anketinin" uygulanmas1 sonucunda ortaya çıkan bölüm ve cinsiyet dağılımı Tablo 2 içerisinde gösterilmiştir. Tüm grup içerisinde İktisat bölümünün ve erkeklerin çoğunlukta olduğu görülmektedir.

Tablo 2.

Anket Temel Demografik Bilgileri

\begin{tabular}{cccccc}
\hline \multicolumn{5}{c}{ Bölümler } & \multirow{2}{*}{ Toplam } \\
\hline \multirow{2}{*}{ Cinsiyet } & & Uluslararası İlişkiler & İktisat & Lojistik & \\
& Erkek & 12 & 35 & 12 & 59 \\
& Kadın & 13 & 16 & 9 & 38 \\
& Toplam & 25 & 51 & 21 & 97 \\
\hline
\end{tabular}


Birinci araştırma sorusuna cevaben, on iki soru içeren Teknolojik Hazırbulunuşluluk anketinin dönem başı ve dönem sonu uygulanmasından elde edilen veriler Tablo 3 içerisinde anketin kendisi, hesaplanan ortalama değeri ve standart sapma değeri (ön test - son test olarak ayrı ayrı) tek tek özetlenmiştir.

Tablo 3.

Verilerin Betimsel İstatistiği

Anket Soruları

Ön Test Son Test

Ort. S.S. Ort. S.S.

1. Teknoloji, insanlara günlük hayatları üzerinde daha fazla kontrol sahibi olma olanağı verir.

2. Teknoloji, insanlara daha fazla hareket özgürlüğ̈̈ verir.

4.120 .954 .280 .69

3. En yeni teknolojiye sahip ürünler kullanım için daha uygundur.

3.511 .233 .791 .03

4. Diğer insanlar yeni teknolojiler hakkında öğüt almak için bana gelirler. 2.411 .112 .691 .02

5. Bir teknoloji ortaya çıktığında arkadaşlar arasında onu ilk alan genelde ben olurum.

6. Diğer insanlardan yardım almadan da yeni teknolojiye sahip ürünlerin nasıl çalıştığını bulabilirim.

3.651 .113 .940 .97

7. Teknik destek hatları yardımcı değildir; çünkü sizin anlayacağınız şekilde açıklamalarda bulunmazlar.

3.131 .163 .431 .16

8. Bir ileri teknoloji ürünü sağlayıcısından veya bir servisten teknik destek alırken benden daha fazla bilgisi olan biri tarafından kullanıldığımı hissediyorum.

9. İnsanlar beni izlerken üst düzey teknolojik bir cihazla ilgili problem yaşamak utanç vericidir.

3.121 .373 .091 .26

10. Sadece online olarak (çevrimiçi) erişilebilecek bir yerle iş yaptığımda kendimi güvende hissetmem.

3.001 .063 .291 .02

11. Bilgisayar üzerinden kredi kart numaramı vermenin güvenli olmadığını düşünüyorum.

12. Elektronik olarak yapılan tüm işlerin daha sonra yazılı olarak doğrulanması gerektiğini düşünüyorum.

Temel betimsel istatistikten sonra veriler üzerinde parametrik olmayan bir analiz olan "iliş̧kisiz ölçümler için Mann Whitney U test" uygulanarak ön test ve son test maddelerinde ayrı ayrı cinsiyetler arası (Erkek/Kadın) fark olup olmadığına bakılmıştır. Analizler sonucunda sadece ön test aşamasında 11. soruda (Bilgisayar üzerinden kredi kart numaramı vermenin güvenli olmadığını düşünüyorum.) cinsiyetler arası fark olduğu tespit edilmiştir (Tablo 3). Sıra ortalamaları dikkate alındığında, bu soruya cevap veren kadın katılımcıların puanının daha yüksek olduğu görülmektedir. Bu durumda kadın katılımcıların erkeklere göre kredi kartı numarası vermenin daha tehlikeli olduğunu düşündükleri söylenebilir.

Tablo 4.

Anket Sorularından Cinsiyete Göre Fark Çıkan 11. Sorunun U-testi Sonucu

\begin{tabular}{cccccc}
\hline Cinsiyet & $\mathrm{n}$ & $\begin{array}{c}\text { Sira } \\
\text { Ortalamas1 }\end{array}$ & Sira Toplamı & $\mathrm{U}$ & $\mathrm{p}$ \\
\hline Erkek & 59 & 44,57 & 2629,50 & 859,50 & 0,045 \\
Kadın & 38 & 55,88 & 2123,50 & & \\
\hline
\end{tabular}


Cinsiyetler arasındaki farklar incelendikten sonra yine bir parametrik olmayan analiz olan "ilişkisiz ölçümler için Kruskal Wallis H-test" ile bölümler arasında (Uluslararası İlişkiler, İktisat, Lojistik) fark olup olmadığı incelenmiştir. Elde edilen analiz sonuçlarına göre sadece ön test 3 (En yeni teknolojiye sahip ürünler kullanım için daha uygundur) ve 8 (Bir ileri teknoloji ürünü sağlayıcısından veya bir servisten teknik destek alırken benden daha fazla bilgisi olan biri tarafindan kullanıldığımı hissediyorum) numaralı sorular içerisinde bölümler arasında fark görülmüştür (Tablo 4). Ortaya çıkan anlamlı farkın hangi gruptan geldiğini görmek için Kruskal Wallis H-testten sonra gruplar içerisinde çoklu olarak Mann Whitney U-testler yapılmalıdır. Yapılan Mann Whitney U-test sonuçlarına göre her iki soru içinde fark sadece Uluslararası İlişkiler ve İktisat bölümleri arasında gözlemlenmiştir. Ortaya çıkan sıra ortalamasında İktisat Uluslararası İlişkilerden daha yüksek bir puana sahiptir.

Tablo 5.

Anket Soruları Üzerinde Bölümlere Göre Kruskal Wallis Testi Sonucu

\begin{tabular}{|c|c|c|c|c|c|c|c|}
\hline Soru & Bölüm & $\mathrm{n}$ & $\begin{array}{l}\text { Sira } \\
\text { Ort. }\end{array}$ & sd. & $X^{2}$ & $\mathrm{p}$ & Anlamlı Fark \\
\hline \multirow[t]{3}{*}{3} & $\begin{array}{l}\text { Uluslararas1 } \\
\text { ilisskiler }\end{array}$ & 25 & 37,88 & \multirow[t]{3}{*}{2} & \multirow[t]{3}{*}{6,798} & \multirow[t]{3}{*}{0,033} & \multirow[t]{3}{*}{$\begin{array}{c}\text { Uluslararası İlişkiler }< \\
\text { İktisat }\end{array}$} \\
\hline & İktisat & 51 & 54,88 & & & & \\
\hline & Lojistik & 21 & 47,95 & & & & \\
\hline \multirow[t]{3}{*}{8} & $\begin{array}{l}\text { Uluslararas1 } \\
\text { ilişkiler }\end{array}$ & 25 & 37,32 & \multirow[t]{3}{*}{2} & \multirow[t]{3}{*}{6,404} & \multirow[t]{3}{*}{0,041} & \multirow[t]{3}{*}{$\begin{array}{c}\text { Uluslararası İlişkiler < } \\
\text { İktisat }\end{array}$} \\
\hline & İktisat & 51 & 53,74 & & & & \\
\hline & Lojistik & 21 & 51,40 & & & & \\
\hline
\end{tabular}

En son analiz olarak yine bir parametrik olmayan test olan "ilişkili ölçümler için Wilcoxon işaretli sıralar testi” uygulanmıştır. "z-test istatistiğinin" kullanıldığı bu teknikte ilişkili olan veriler hem fark puanlarının yönü hem de sıra miktarları açısından analize katılır. Anket verileri üzerinden yapılan analizin sonuçları Tablo 5 'de yer almaktadır. Tablodan da görülebileceği gibi soru 4, 6, 10,11, 12 üzerinde ön ve son test sonuçlarına göre anlamlı fark oluşmuştur. Son üç sorunun güvenlik boyutunda olduğu düşünülürse bu sorulardaki değişime dikkat edilmelidir.

Tablo 6.

Anket Sorularına Uygulanan Wilcoxon İşaretli Sıralar Testi

\begin{tabular}{|c|c|c|c|c|c|c|}
\hline Soru Numarası & $\begin{array}{c}\text { Sontest- } \\
\text { Öntest }\end{array}$ & $\mathrm{n}$ & $\begin{array}{c}\text { Sira } \\
\text { Ortalamas1 }\end{array}$ & $\begin{array}{c}\text { Sira } \\
\text { Toplamı }\end{array}$ & $\mathrm{Z}$ & $\mathrm{p}$ \\
\hline \multirow{3}{*}{$\begin{array}{l}\text { 4: Diğer insanlar yeni } \\
\text { teknolojiler hakkında öğüt } \\
\text { almak için bana gelirler. }\end{array}$} & Negatif Sira & 28 & 34,02 & 952,50 & 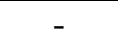 & \multirow[t]{3}{*}{0,036} \\
\hline & Pozitif Sıra & 44 & 38,08 & 1675,50 & $2,097^{*}$ & \\
\hline & Eşit & 25 & & & & \\
\hline \multirow{3}{*}{$\begin{array}{l}\text { 6: Diğer insanlardan yardım } \\
\text { almadan da yeni teknolojiye } \\
\text { sahip ürünlerin nasıl } \\
\text { çalıştığını bulabilirim. }\end{array}$} & Negatif Sira & 30 & 28,68 & 860,50 & - & \multirow[t]{3}{*}{0,050} \\
\hline & Pozitif Sira & 38 & 39,09 & 1485,50 & $1,958^{*}$ & \\
\hline & Eşit & 29 & & & & \\
\hline \multirow{3}{*}{$\begin{array}{l}\text { 10: Sadece online olarak } \\
\text { (çevrimiçi) erişilebilecek bir } \\
\text { yerle iş yaptığımda kendimi } \\
\text { güvende hissetmem. }\end{array}$} & Negatif Sira & 27 & 36,83 & 994,50 & - & \multirow[t]{3}{*}{0,045} \\
\hline & Pozitif Sıra & 46 & 37,10 & 1706,50 & $2,004^{*}$ & \\
\hline & Eşit & 24 & & & & \\
\hline \multirow{3}{*}{$\begin{array}{l}\text { 11: Bilgisayar üzerinden kredi } \\
\text { kart numaramı vermenin } \\
\text { güvenli olmadığını } \\
\text { düşünüyorum. }\end{array}$} & Negatif Sıra & 23 & 33,28 & 765,50 & - & \multirow[t]{3}{*}{0,007} \\
\hline & Pozitif Sira & 46 & 35,86 & 1649,50 & $2,691^{*}$ & \\
\hline & Eşit & 28 & & & & \\
\hline
\end{tabular}




\begin{tabular}{lllcccc}
\hline 12: Elektronik olarak yapılan & Negatif Sıra & 24 & 36,77 & 882,50 & - & 0,021 \\
tüm işlerin daha sonra yazılı & Pozitif Sıra & 47 & 35,61 & 1673,50 & $2,303^{*}$ & \\
$\begin{array}{l}\text { larak doğrulanması } \\
\text { gerektiğini düşünüyorum. }\end{array}$ & Eşit & 26 & & & & \\
\hline
\end{tabular}

* Negatif sıralar temeline dayalı

\section{Tartışma ve Sonuç}

$\mathrm{Bu}$ çalışmanın temel amacı herhangi bir teknolojiyi kullanma öncesinde olumlu manada bulunması beklenen teknolojik hazırbulunuşluluk olgusunun İktisadi ve İdari Bilimler Fakültesinin üç bölümünün (Uluslararası İlişkiler, İktisat, Lojistik) birinci sınıf öğrencilerinin aldıkları Bilgisayar uygulamaları dersinde nasıl değiştiğini tespit etmektir. Bu amaca hizmet etmek üzere iki araştırma sorusu tasarlanmıştır; öğrencilerin ders öncesi ve sonrası teknolojik hazırbulunuşlulukları nasıldır ve öğrencilerin teknolojik hazırbulunuşlulukları cinsiyet ve bölüm değişkenlerine göre anlamlı bir fark göstermekte midir.

Uygulanan ön test ve son test sonuçlarına göre olumlu anlam içeren maddelerde bir ilerleme ve olumsuz anlam içeren maddeler de ise gerileme tespit edilmiştir. Bu durum temel olarak ortalama ve standart sapmalara bakıldığında söz konusu dersin bir değişime neden olduğu söylenebilir. Bu durumun daha detaylı tespiti adına yapılan analizler de ise toplam on iki maddeden oluşan anket içerisinde beş maddede ön-son test zaman değişkenine göre istatistiksel olarak anlamlı bir farkın oluştuğu görülmektedir. $\mathrm{Bu}$ beş maddeden üçünün teknolojinin güvenliği boyutunda olduğuna dikkat çekerek olası şu sonuca varılabilir; öğrenciler teknolojiyi sadece olumlu yönleriyle algılamanın bir adım ötesine giderek teknolojinin güvenlik sorunlarına yönelik konularda bir farkındalık oluşturdukları ve buna bağlı olarak teknolojiyi kullanma isteği ve motivasyonu konusunda olumsuzluk oluşturacak durumlarının üstesinden gelmişlerdir. Diğer bir ifadeyle, dersin sonunda güvenlik boyutunda teknolojik hazırbulunuşlulukları yükselmiş olabilir.

Güvenlik konusu birçok teknolojiyle alakalı dersin ana konuları arasında bulunmaktadır. Çalışma içerisinde sözü edilen dersin bir haftasının açıktan bilgisayar güvenliği üzerine olması söz konusu değişimi tetiklemiş olabilir. Bu konuda Chen ve Tao'nun (2012) belirttiği gibi birçok bilgisayar güvenlik dersi sadece uygulamalı laboratuvar alıştırmaları şeklinde tasarlanmaktadır. Oysa bu dersler sistem güvenliği, ağ güvenliği ve internet güvenliği gibi bilgisayar güvenlik alıştırmalarını da içermelidir. Hatta birçok üniversitenin öğretim programı bilgisayar güvenliği ve bilgisayarın yanlış kullanımı konularını içermemektedir (Foltz ve Renwick, 2011; White ve diğerleri, 2013). Fakat bilgisayar ve iletişim teknolojileri içerisinde güvenlik ile ilgili konuların öğretimi teknoloji, politika, yönetim, davranış, ekonomi ve yasal boyut gibi geniş kapsamlı konuları içerdiğinden teknik olarak çok zordur (He ve diğerleri, 2013). Hatta bu konuda maalesef lisans öğrencileri için internet güvenliği ile ilgili basılan kitap sayısı çok azdır (Chen ve Tao, 2012).

Günümüzde bilgisayar ve bilgi güvenliği konularının öğretimi eğitim kurumlarının hem kritik hem de önemli görevleri arasındadır (Lomo-David, Acilar, Chapman ve Shannon, 2011). Bilgi güvenliği, bilginin dijitalleşmesinin küresel ve yerel anlamda etkileri, siber savaşlar, sosyal medyanın güvenli kullanımı gibi teorik konular yanında şifreleme, bilgisayar sistemlerinin güvenlik taramaları, anti-virüs yazılımlarının kullanımı, güvenlik duvarı koruması gibi pratik konuların da ders kapsamında öğretilmesi uygun olacaktır.

Tek bir madde üzerinden genel bir yorum çıkarmak zor olsa dahi alanyazında (Badri ve diğerleri, 2014; Lee, Yeung ve Ip, 2017; Moftakhari, 2013; Tsourela ve Roumeliotis, 2015) tartışılan cinsiyetin teknolojik hazırbuluşluluğu etkilediği yorumu bu çalışma içerisinde de gözlenmiştir. Teknolojik hazırbulunuşluluğu ve cinsiyet karşılaştırmalarında alanyazında farklı sonuçlar yer almaktadır. Bu çalışma içerisinde sadece bir soru üzerinde cinsiyet değişkenine bağlı olarak değişim gözlenmiştir; kadın katılımcıların erkeklere göre kredi kartı numarası vermenin daha tehlikeli olduğunu düşündükleri söylenebilir. Ortaya çıkan farkın yine güvenlik konusunda oluşması dikkate değerdir. Farklı araştırmalar (He, Yuan ve Yang, 2013; White, Hewitt ve Kruck, 2013) içerisinde de söz edildiği gibi günümüzde teknoloji kullanımı ve 
hazırbulunuşluluğu söz konusu olduğunda akla ilk gelen şey güvenliktir. Her gün medyada sözü edilen güvenlikle alakalı olumsuz durumlar bunu açıkça tetiklemiş olabilir. Parasuraman (2000) tarafından sıklıkla sözü edilen güvensiz olma durumun teknolojik hazırbuluşluluğunu olumsuz etkilemesi durumu bu çalı̧̧ma içerisinde dersin bir sonucu olarak azalmış görünmektedir.

Erdoğan ve Bulut (2015) tarafından da ifade edildiği gibi teknoloji hazırbulunuşluluğu konusu İktisadi ve İdari Bilimler Fakültesi çerçevesinde ihmal edilen bir konudur. Bu çalışma içerisinde Uluslararası İlişkiler, İktisat ve Lojistik bölümleri arasında yapılan karşılaştırmaya göre sadece ön test soru 3 (En yeni teknolojiye sahip ürünler kullanım için daha uygundur) ve soru 8 (Bir ileri teknoloji ürünü sağlayıcısından veya bir servisten teknik destek alırken benden daha fazla bilgisi olan biri tarafından kullanıldığımı hissediyorum) üzerinde bölüm değişkenine bağlı olarak anlamlı bir fark tespit edilmiştir. Ortaya çıkan sonuca göre bu iki madde üzerinde İktisat bölümünün puanı Uluslararası İlişkilerden daha yüksektir. Ders sonunda yapılan son test üzerinde ise bölümler arasında bir fark tespit edilememiştir. Bu durum Moftakhari’nin (2013) teknoloji hazırbulunuşluluğunun bölümlere göre değiştiği konusundaki çalışmasıya çelişmektedir.

$\mathrm{Bu}$ çalışmanın sınırlılıkları konusuna da yoğunlaşıldığında ise karşımıza ilk olarak araştırmacının kullanmış olduğu çalışma deseninde bu desene özel iç geçerlilik problemi ortaya çıkmaktadır. Bu problemin en önemli örneği öğrencilerin geçmişleridir. Bir başka deyişle, herhangi bir kontrol grubu olmadığı için araştırmacı ön test ve son test arasında başka herhangi bir olayın değişime neden olup olmadığını kesin olarak söyleyememektedir. Bu nedenle bir başka çalışma içerisinde bir kontrol grubu üzerinden karşılaştırılmalı olarak teknolojik hazırbulunuşluluğu çalışılabilir.

Gelecekte yapılacak olan diğer bilimsel çalışmalar, bireylerin teknolojik hazırbulunuşluluklarındaki zamana bağlı değişiklikleri izlemek adına uzun vadeli (longitudinal) tasarlanabilir. Ayrıca, teknoloji hazırbulunuşluluğu hakkındaki tüm resmin daha ayrıntılı bir şekilde anlaşılması için daha büyük bir örneklem grubu üzerinde gelecekte yeni bilimsel çalışmalar yapılabilir.

\section{Kaynaklar}

Amron, M. T., Ibrahim, R. ve Chuprat, S. (2017). A review on cloud computing acceptance factors. Procedia Computer Science, 124, 639-646.

Badri, M., Al Rashedi, A., Yang, G., Mohaidat, J. ve Al Hammadi, A. (2014). Technology readiness of school teachers: An empirical study of measurement and segmentation. Journal of Information Technology Education: Research, 13, 257-275.

Chen, L.-C. ve Tao, L. (2012). Teaching Web Security using Portable Virtual Labs. Educational Technology \& Society, 15(4), 39-46.

Chung, N., Han, H. ve Joun, Y. (2015). Tourists' intention to visit a destination: The role of augmented reality (AR) application for a heritage site. Computers in Human Behavior, 50, 588-599.

Elitaş, C. ve Koçyiğit, S. Ç. (2015). İşletme bölümü öğrencilerinin Facebook kullanım amaçlarını ve eğitsel bağlamda kullanımı ile ilgili görüşlerini belirlemeye yönelik bir araştırma: Gazi Üniversitesi örneği. Muhasebe Bilim Dünyası Dergisi, 17(1), 159-192.

Erdoğan, E. ve Bulut, E. (2015). İşletme bölümü öğrencilerinin memnuniyet düzeylerini etkileyen faktörlerin araştırılması. Uluslararası Yönetim İktisat ve Işsletme Dergisi, 11(26), 151-169.

Foltz, C. B. ve Renwick, J. S. (2011). Information systems security and computer crime in the $1 \mathrm{~s}$ curriculum: A detailed examination. Journal of Education for Business, 86, 119-125.

Fraenkel, J. R. ve Wallen, N. E. (2000). How to design and evaluate research in education (4th ed.). New York: McGraw-Hill.

He, J. ve Freeman, L. A. (2010). Are men more technology-oriented than women? The role of gender on the development of general computer self-efficacy of college students. Journal of Information Systems Education, 21(2), 203-212. 
He, W., Yuan, X. ve Yang, L. (2013). Supporting Case-based Learning in Information Security with Web-based Technology. Journal of Information Systems Education, 24(1), 31-40.

Hung, M.L., Chou, C., Chen, C.H. ve Own, Z.Y. (2010). Learner readiness for online learning: Scale development and student perceptions. Computers \& Education, 55(3), 1080-1090.

Lee, C., Yeung, A. S. ve Ip, T. (2017). University English language learners' readiness to use computer technology for self-directed learning. System, 67, 99-110.

Liljander, V., Gillberg, F., Gummerus, J. ve Riel, A. (2006). Technology readiness and the evaluation and adoption of self-service technologies. Journal of Retailing and Consumer Services, 13, 177-191.

Lin, C. H., Shih, H.Y. ve Sher, P.J. (2007). Integrating technology readiness into technology acceptance: The TRAM model. Psychology \& Marketing, 24(7), 641-657.

Ling, L. M. ve Moi, C. M. (2007). Professional students' technology readiness, prior computing experience and acceptance of an e-Learning system. Malaysian Accounting Review, 6(1), 85-99.

Lomo-David, E., Acilar, A., Chapman, B. F. ve Shannon, L. J. (2011). University students' computer security practices in two developing nations: A comparative analysis. Business Studies Journal, 3(2), 63-76.

Moftakhari, M. M. (2013). Evaluating e-learning readiness of faculty of letters of Hacettepe (Yayımlanmamış yükssek lisans tezi). Hacettepe Üniversitesi, Ankara.

Nielsen, S. C. ve Welch, D. (2003). Teaching strategy and security in cyberspace: An interdisciplinary approach. International Studies Perspectives, 4, 133-144.

Nugroho, M. A. ve Fajar, M. A. (2017). Effects of technology readiness towards acceptance of mandatory web-based attendance system. Procedia Computer Science, 124, 319-328.

Nugroho, M. A., Susilo, A. Z., Fajar, M. A. ve Rahmawati, D. (2017). Exploratory study of SMEs technology adoption readiness factors. Procedia Computer Science, 124, 329-336.

Özgan, H. ve Tekin, A. (2011). Öğrencilerin hazırbulunuşluk düzeylerinin sınıf yönetimine etkisine yönelik öğretmen görüşleri. Mustafa Kemal Üniversitesi Sosyal Bilimler Enstitüsü Dergisi, 8(15), 421-434.

Öztürk, S. ve Kutlu, H. A. (2017). Muhasebe eğitiminde teknoloji kullanılmasına öğrencilerin bakış1: Kafkas üniversitesi'nde bir araştırma. Muhasebe Bilim Dünyası Dergisi, 19(3), 781-799.

Parasuraman, A. (2000). Technology readiness index (Tri): A multiple-item scale to measure readiness to embrace new technologies. Journal of Service Research, 2(4), 307-320.

Ratliff, V. (2009). Are college students prepared for a technology-rich learning environment? MERLOT Journal of Online Learning and Teaching, 5(4), 698-702.

Sim, I., Liginlal, D. K. ve Khansa, L. (2012). Information privacy situation awareness: Construct and validation. Journal of Computer Information Systems, Fall, 57-64.

Sönmez, E. ve Akgül, H. (2015). Üniversite öğrencilerinin teknolojiye hazır bulunuşluk düzeyi ve kişilik özellikleri arasındaki ilişki: Erciyes Üniversitesi örneği. Yönetim Bilimleri Dergisi, 13(26), 305-327.

Şahin, A. E. (2009). Eğitim fakültesinde hizmet kalitesinin eğitim fakültesi öğrenci memnuniyet ölçeği (ef-ömö) ile değerlendirilmesi. Hacettepe Üniversitesi Eğitim Fakültesi Dergisi, 37, 106-122.

Tsourela, M. ve Roumeliotis, M. (2015). The moderating role of technology readiness, gender, and sex in consumer acceptance and actual use of technology-based services. Journal of High Technology Management Research, 26, 124-136.

Tunç, A., Belli, A. ve Aydın, A. (2017). Kent kimliği ile internet kullanımı arasındaki ilişkinin belirlenmesi: Üniversite öğrencileri üzerine bir alan araştırması. Süleyman Demirel Üniversitesi İktisadi ve İdari Bilimler Fakültesi Dergisi, 22(15), 1673-1688.

Varıc1, İ. ve Bulut, E. (2015). Muhasebe dersine yönelik endişeler ve tutumlar: Samsun Ondokuzmayıs Üniversitesi İktisadi ve İdari Bilimler Fakültesi örneği. Atatürk Üniversitesi Sosyal Bilimler Enstitüsü Dergisi, 19(3), 293-314. 
Walstrom, K. A., Thomas, C. E. ve Weber, A. (2010). Changes in student computer technology attitudes over 20 years: 1988 to 2009. Journal of Computer Information Systems, Winter, 81-86.

Westjohn, S. A., Arnold, M. J., Magnusson, P., Zdravkovic, S. ve Zhou, J. X. (2009). Technology readiness and usage: A global-identity perspective. Journal of the Academy of Marketing Science, 37(3), 250-265.

White, G. L., Hewitt, B. ve Kruck, S. E. (2013). Incorporating global information security and assurance in I.S. education. Journal of Information Systems Education, 24(1), 11-16.

Yağc1, M., Sirakaya, D. A. ve Özüdoğru, G. (2015). The investigation of attitude and readiness of information and communication technologies pre-service teachers toward web based learning. Procedia - Social and Behavioral Sciences, 174, 1099-1106.

Yükseköğretim Bilgi Yönetim Sistemi (2018). Eğitim birimlerine göre ögrenci ve öğretim elemanları sayıları. Erişim adresi: https://istatistik.yok.gov.tr/

\section{Extended Abstract}

\section{Introduction}

In a rapidly changing world, human beings have been making a great effort to adapt themselves to emerging technological developments. Numerous information and communication technology tools have appeal to every segment of society, triggering intense technological knowledge acquisition processes. As a result, profound changes are observed in different social groups and in different professions (Özgan \& Tekin, 2011). For this reason, technology readiness appears as an unprecedentedly important concept and phenomenon.

Sönmez and Akgül (2015) describe technology readiness as being ready for any activity from cognitive, affective, social and psychomotor dimensions. Hence, in order for any work to be carried out, it is the status of the individual who will do the job with the required competence. In a more specific definition, Ling and Moi (2007) define technology readiness as the tendency of individuals to adopt and use new technologies in order to achieve their goals in private and business life. In other words, technology readiness makes an individual ready to enter a new level of technology (Nugroho, Susilo, Fajar, \& Rahmawati, 2017).

The literature shows differences in terms of the interaction of technology readiness with different variables. For example, Tsourela and Roumeliotis (2015) found that technological readiness, gender and age variables affect the willingness and utilization of technologies in real life. Badri et al. (2014), in their study on factors affecting technology readiness, noted that technology readiness is significantly affected by variables such as gender, culture, age and previous education experience. For example, Badri et al. report that men have more advanced technology readiness than women where Moftakhari (2013) reports similar findings. In addition, the same study demonstrated that technology readiness significantly differed in accordance with university departments. In another study, Hung, Chou, Chen and Own (2010) indicated that the school year at the university has an impact on technology readiness. It was found that third and fourth grade students exhibited a much higher technology readiness compared to the first and second grade students.

As a result, schools today need to offer more opportunities that are educational by adding technology readiness to basic needs such as literacy or mathematics (Ratliff, 2009). The strong support of the school to the student can eliminate the factors of insecurity and discomfort that may adversely affect the technology readiness (Nugroho \& Fajar, 2017). In addition, governmental strategies play an important role in technology readiness (Nugroho, Susilo, Fajar, \& Rahmawati, 2017).

\section{Method}

The aim of this research is to investigate whether the Computer Applications course, which is offered for the freshman students of the Faculty of Economics and Administrative Sciences in 
three different departments (International Relations, Economics and Logistics), contributed to a change in students' technology readiness. The following questions are sought in this research:

- What is the technology readiness of students before and after the course?

- Does students' technology readiness differ significantly according to gender and department variables?

In order to serve this purpose, a pre-test $\&$ post-test research design pattern was adopted alongside quasi-experimental quantitative research methods. Subsequent to the study permission, the instrument was distributed to the students at the second hour in the first week of the course (following the introduction of the instructor in the first hour) and the last hour before the final exam in the last week, and data was collected accordingly. Then, the collected data was entered into SPSS and necessary analysis and interpretations were reported accordingly. As a result, the researcher had access 97 students from three different departments (International Relations, Economics and Logistics) of the Faculty of Economics and Administrative Sciences at a private university in Istanbul, Turkey.

The researcher used the instrument developed by Liljander, Gillberg, Gummerus and Riel (2006) which was originally based on Parasuraman (2000), in order to make the most effective measurement with minimum questions from technology readiness studies. The survey consists of 12 questions on 5-point Likert scale from 'strongly agree' to 'strongly disagree'. The researcher worked on the survey item-by-item. Four basic demographic questions are presented to the students before the survey; gender, department, whether they have a computer or not and type of computer (desktop or laptop). Then, the normality test was applied to see the distribution of the data firstly on the survey, separately for the pre-test and post-test data. The results showed that normal distribution hypothesis is rejected with a $95 \%$ confidence interval. For this reason, it was decided to use non-parametric tests in the study.

\section{Result and Discussion}

According to the pre-test and post-test results, there was an improvement in items with positive meaning and a decline in the items containing negative meaning. Those results could be interpreted as an effect of the course on technology readiness. Further analysis of this situation in the direction of more detailed analysis of the 12 items in the survey of a statistically significant difference is observed in five items. It can be concluded that three of these five items are under the dimension of technology safety where the students have created awareness toward the security problems of technology. In other words, at the end of the course, technological readiness increased in the security dimension.

Today, teaching computer and information security issues are both critical and important tasks of educational institutions (Lomo-David, Acilar, Chapman \& Shannon, 2011). Besides the theoretical issues such as information security, global and local effects of the digitalization of information, cyber warfare, the safe use of social media, it will be appropriate to teach practical topics such as encryption, security scans of computer systems, use of antivirus software, and firewall protection.

Even if it is difficult to make a general comment on a single item, the role of gender discussed in the literature (Badri et al., 2014; Lee, Yeung \& Ip, 2017; Moftakhari, 2013; Tsourela \& Roumeliotis, 2015) was observed in this study. There are different results in the literature on the relationship between technology readiness and gender. In this study, only one question was observed based on gender variable; female participants think it is more dangerous to give credit card numbers than men. It is noteworthy that the difference occurred again in terms of security. As mentioned in different studies (He, Yuan \& Yang, 2013; White, Hewitt \& Kruck, 2013), the first thing that comes to mind when it comes to technology use and readiness is security. Security-related unfavorable situations in the media may have clearly triggered this. Parasuraman (2000) often mentioned by the insecurity of the technology readiness to adversely affect the situation in this study as a result of the course seems to have decreased.

As stated by Erdoğan and Bulut (2015), the subject of technology readiness is neglected within the framework of the Faculty of Economics and Administrative Sciences. According to 
the comparison between the departments of International Relations, Economics and Logistics, only the pre-test question 3 and question 8 showed significant differences. According to the result, the average scored of Economics was higher than International Relations on these two items. At the end of the course, there was no difference between the departments. This contradicts with the results of Moftakhari's (2013) study, which noted that technology readiness changes with respect to departments. 